\title{
GESTÃO E PRECONCEITO RACIAL
}

http://dx.doi.org/10.5902/217621717957

\author{
Jacilda de Siqueira Pinho \\ Escola Estadual Irmã Lucinda Facchini, Brasil.
}

\begin{abstract}
Resumo
O presente artigo reflete a situação de crianças negras na Escola Estadual Irmã Lucinda Facchini, situada no Bairro da Ponte, município de Diamantino, Mato Grosso. Foram feitas entrevistas com diretores, coordenadores e alunos. As entrevistas evidenciaram que a escola procura priorizar o trabalho com a diversidade étnica. Os entrevistados concebem que existe a mistura de raça no Brasil, porém, concordam que o currículo escolar não discute este problema no planejamento pedagógico que se percebe um rápido enfoque em relação ao assunto. Percebe-se, ao longo deste trabalho, que os entrevistados sentem-se desconfortáveis ao tocar no assunto, demonstraram que existe uma névoa de insatisfação pairando sobre a escola. Por fim, sugere-se que os gestores programem ações como projetos pedagógicos e atividades que abordem francamente de forma desmascarada a discriminação racial.
\end{abstract}

Palavras-chave: desigualdades, gestão, discriminação.

\section{MANAGEMENT AND PREJUDICE RACIAL}

\section{Abstract}

This article reflects the situation of black children lived in the State School Sister Lucinda Facchini, located in Bairro da Ponte, City of Diamond, Mato Grosso. Interviews were conducted with the school management team: director, coordinator and students. The interviews revealed the School seeks to prioritize work with ethnic diversity. Respondents perceive that there is a mixture of race in Brazil, however, agree that the curriculum does not discuss this issue in educational planning, we can see a rapid approach to the subject. It can be seen throughout this paper that the respondents are uncomfortable to touch this subject, demonstrated that there is a fog of dissatisfaction hanging over the school. Finally it is suggested that managers implement actions such as: Educational Projects and activities that deal frankly so unmasked racial discrimination. Key-words: inequalities, management, discrimination. 


\section{Introdução}

omo forma de complementar a Lei de Diretrizes e Bases da Educação, foram criados os parâmetros curriculares nacionais, que propõem a abordagem da pluralidade cultural como um tema transversal que, segundo Silva (2002) tem como objetivo possibilitar o conhecimento do patrimônio étnico-cultural brasileiro.

Os PCNs abordam questões relevantes quanto à questão racial em sala, mas por si só não dão conta deste tema tão delicado que é o das relações raciais no cotidiano da sala de aula. Muitos professores "relativizam as diferenças, tratando-as como pluralidade de experiências sem analisar que no modelo socioeconômico diferença é sinônimo de desigualdade" (Silva, 2002, p. 33).

A naturalização das desigualdades étnico-raciais no Brasil opera de modo eficiente dificultando um olhar mais cuidadoso sobre os resultados dessas desigualdades no sistema educacional. Pode-se observar que o currículo da escola não dá tratamento devido a questão. A discussão da situação da criança e do jovem negro e do mestiço não tem suscitado muito interesse nas reflexões educacional brasileira.

A Escola Irmã Lucinda Facchini tem como função social a tarefa de modificar o comportamento das pessoas, tornando-as mais humanas, mais solidarias e mais felizes, propiciar aos alunos em sua coletividade uma situação de aprendizagem prazerosa, estimulante e motivadora. Assim, a função social desta escola está condizente com discussões atuais, porém está distante na prática do que se almeja.

$\mathrm{Na}$ sociedade moderna fica reservada à escola grande parcela do ensino reconhecido socialmente como tal. Dessa maneira, o currículo deve ser concebido como um objeto de estudo e como forma de organização do conhecimento escolar. Como salienta Lopes (2006, p. 16) "o currículo vivenciado pelos alunos vai além dos conteúdos escolhidos para serem ministrados pelos professores. A existência, na experiência escolar de um currículo oculto ao lado do currículo oficial está confirmada por vários estudos sobre o tema."

Desta forma, segundo Lopes (2006, p.17) "o currículo oculto inclui conteúdos não ditos, valores morais e explicados nos olhares e gestos, apreciações e repreensões de condutas, aproximações e repulsas de afetos, legitimações e indiferenças em relação as atitudes, escolhas e preferências."

Ao contemplarmos as relações raciais dentro do espaço escolar vimos que a escola não está sendo coerente com a sua função social quando se propõe a ser um espaço que preserva a diversidade cultural, responsável pela promoção da equidade. Observa-se que o tratamento às questões raciais não é detalhada e específica, no entanto, poderá ser perpassada em meio aos projetos.

Silva (2000, p. 33) afirma que

os PCN's podem oferecer diretrizes importantes políticos-educacionais para as propostas curriculares a serem formuladas pelas secretarias de educação e educadores não se detiverem a uma leitura superficial e enviesada que relativiza as diferenças, tratando-as como pluralidade de experiência, sem analisar que no modelo socieconômico brasileiro, diferença é sinônimo de desigualdade". 
Sobre isso Menezes (2002, p. 8) confirma que "o cotidiano escolar vai dando indícios do lugar do negro nesse espaço. Muitas crianças acabam resignando-se a esse nãoreconhecimento, a ponto de se avaliarem de maneira distorcida, considerando-se incapazes, inferiores e, ao menor sinal de dificuldade, abandonam o processo escolar."

Assim, a questão da discriminação racial aos negros ou aos descendentes africanos não é tratada de modo reflexivo, levando em conta a realidade em sala de aula. A escola e os professores precisam rever valores e princípios arraigados a concepções do mundo e das pessoas que justificam práticas e sentimentos racistas.

Lopes (2006, p. 28) sinaliza que a "lei 10.639/03 procura reparar conteúdo que dizem respeito a todos os brasileiros e que foram ocultados e omitidos historicamente pela sociedade e pela escola". Esta lei promove movimentos no campo da identidade, dos direitos culturais e do conhecimento e tem como meta uma política de igualdade social, buscando a alteração nos indicadores sociais brasileiros.

Lopes $(2006$, p. 24) leva a refletir que "é preciso que o professor esteja aberto para perceber a sua atuação, pois, de fato a "naturalização" das desigualdades étnico-raciais no Brasil opera de modo eficiente, dificultando um olhar mais cuidadoso sobre os resultados dessas desigualdades nas praticas de cada um e no sistema educacional".

Nesse sentido, cabe enfatizar que o princípio estruturador das ações e projetos pedagógicos é a igualdade. Esta igualdade pressupõe semelhança e diferenças, mas não contempla a inferioridade que é a marca do preconceito e da discriminação social. Temos que ter a consciência de que somos todos iguais e humanos. E essa concepção que precisamos ultrapassar nos programas curriculares, nas pesquisas e escolhas de conteúdo.

Percebe-se que ao longo deste trabalho os entrevistados sentem-se pouco à vontade, demonstrando que existe uma névoa de insatisfação que a escola como disseminadora de pensamentos não dá conta e não traz respostas satisfatória, não responde aos anseios dos alunos. Mesmo com a obrigatoriedade da lei n. 10.639, de 9 de janeiro de 2003, a escola ainda caminha a passos lentos para cumprir o que ela estabelece.

Silva (2002, p.38) conclui que "a sistemática negação de uma justa imagem "do outro", a negação e a visão estereotipada dos negros, é um dos mecanismos mais violentos vividos na escola". A opção nos currículos é considerada um meio para recuperação dos fatos e superação da visão eurocêntrica dos conteúdos, funciona como um elemento de valorização da população negra por meio do conhecimento de suas origens.

Cavalleiro (2006, p. 23) destaca que "o silencio das escolas sobre as dinâmicas das relações raciais tem permitido que seja transmitida aos (as) alunos (as) uma pretensa superioridade branca, sem que haja questionamento desse problemas por parte dos (a) profissionais da educação e envolvendo o cotidiano escolar em praticas prejudiciais ao grupo negro."

Deve-se levar em conta que os centros de formação não dispõem de formadores capacitados para discutir e sanar dúvidas sobre essas diretrizes. Sobre isso Cavalleiro (2006, p. 23) afirma que "um olhar atento para a escola capta situações que configuram de modo expressivo atitudes racistas. Nesse espectro, de forma objetiva ou subjetiva, a 
educação apresenta preocupações que vão do material didático-pedagógico à formação de professores".

É importante que os agentes educativos procurem eliminar os fatores negativos prejudiciais ao progresso de uma cidadania equilibrada: discriminação da diferença e encontrem fatores que promovam o respeito por si mesmo e pelos outros.

\section{Metodologia}

Para a realização do presente trabalho foi realizada uma pesquisa quantitativa na Escola Estadual Irmã Lucinda Facchini, situada no Bairro da Ponte, município de Diamantino, Mato Grosso. Esta escola está em funcionamento há 34 anos, atende a dois turnos, com 405 alunos e atende o $2^{\circ}$ e $3^{\circ}$ ciclo do ensino fundamental. Tem como missão oferecer um ensino de qualidade e excelência, que propicie oportunidades de se apropriar dos conhecimentos acumulados pela humanidade.

O questionário foi aplicado a alunos, funcionários e gestores da escola no mês de junho de 2012.

\section{Resultado e discussão}

Depois dos dados compilados chegou aos resultados abaixo apresentados. Observa-se, pela figura 1, que a maioria dos entrevistados sabe o que é discriminação racial.

Figura 1 - Você sabe o que é discriminação racial?

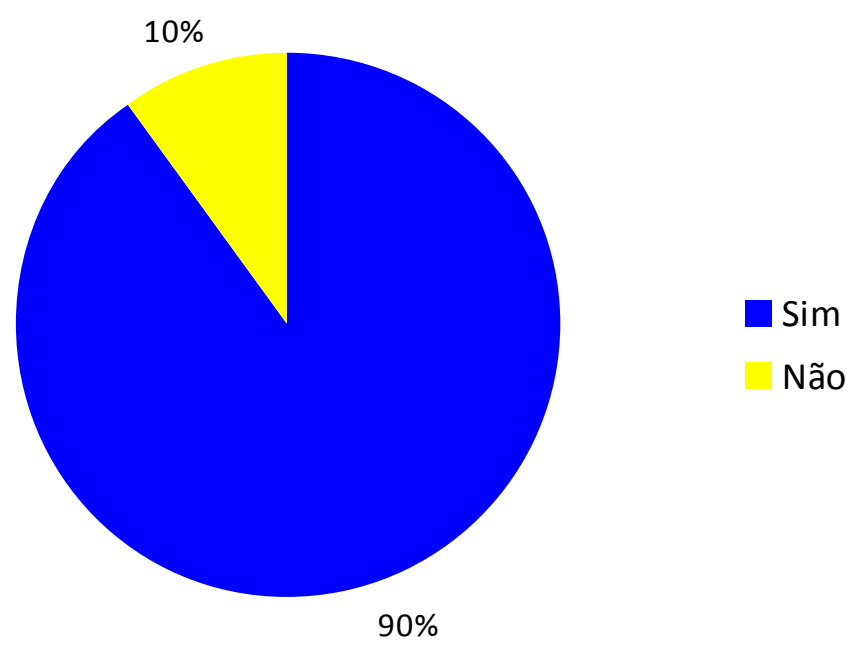


Pela figura 2 observa que a maioria dos entrevistados, sabem o que é bullying.

Figura 2 - Você sabe o que é bullying?

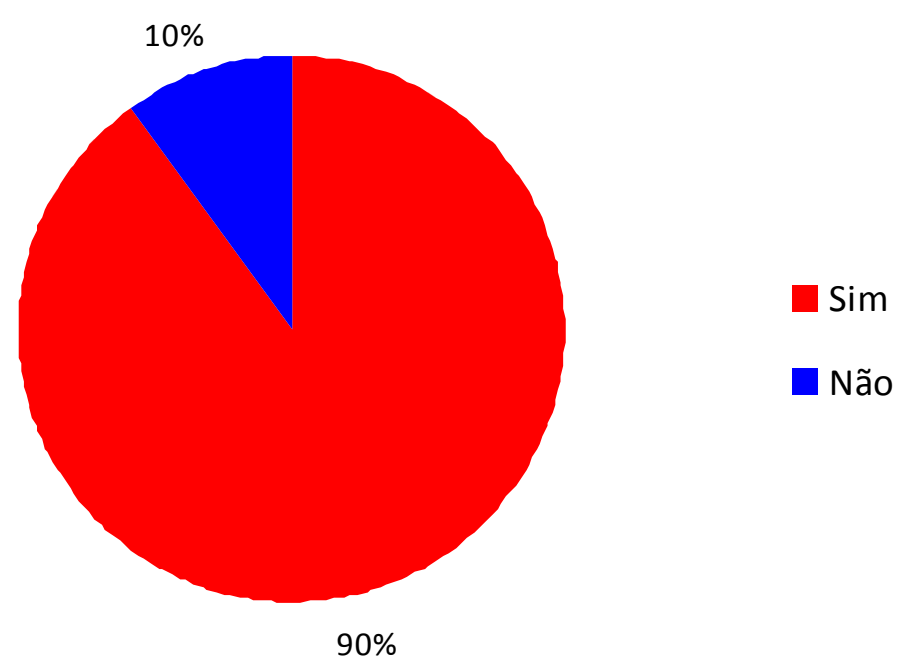

Pela figura 3 percebe-se que a maioria dos entrevistados já percebeu racismo na escola.

Figura 3 - Você já percebeu racismo na escola?

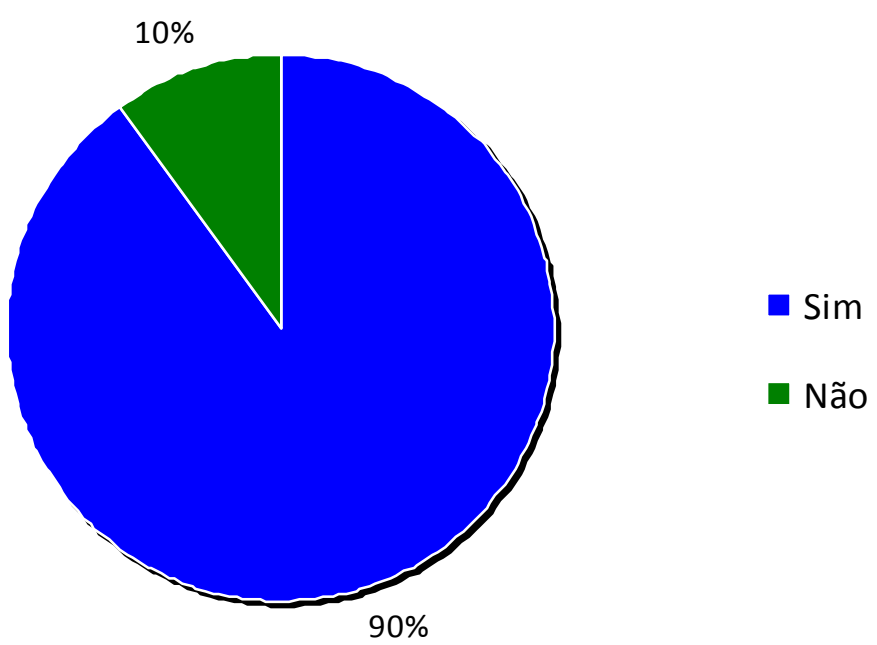


Pela figura 4, 80\% dos entrevistados já percebeu bullying na escola.

Figura 4 - Você já percebeu bullying na escola?

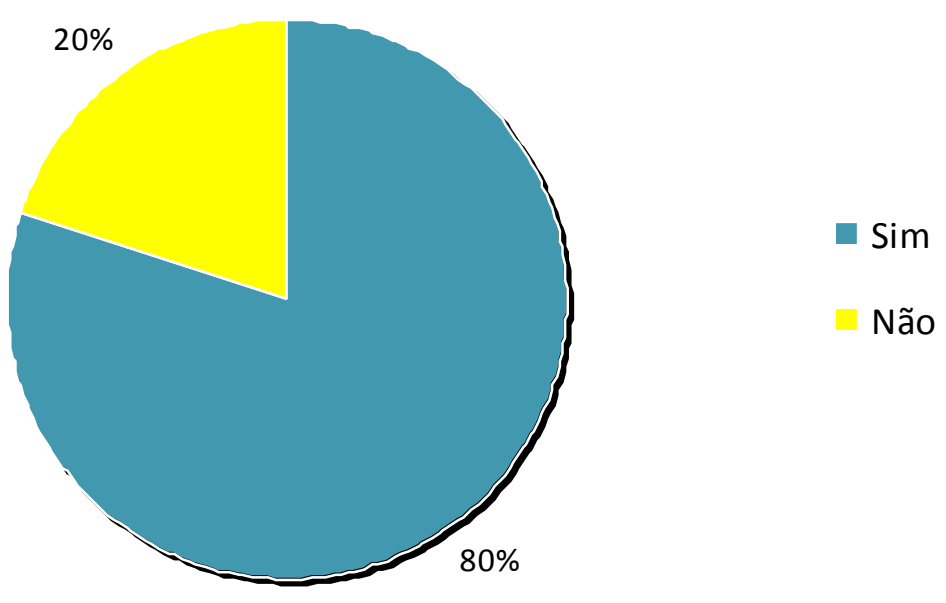

Pela figura $5,80 \%$ dos entrevistados já presenciou racismo com seu colega.

Figura 5 - Você presenciou racismo com seu colega?

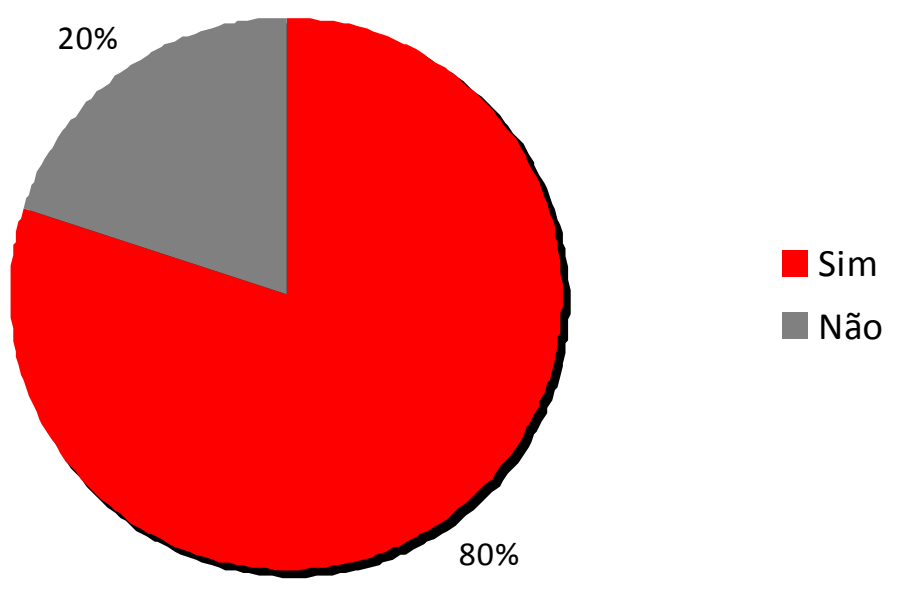


Pela figura 6 observa-se que $70 \%$ já perceberam situações de racismo entre colegas e $30 \%$ presenciou situação de racismo de funcionários para com aluno.

Figura 6 - Em quais situações você percebeu o racismo?

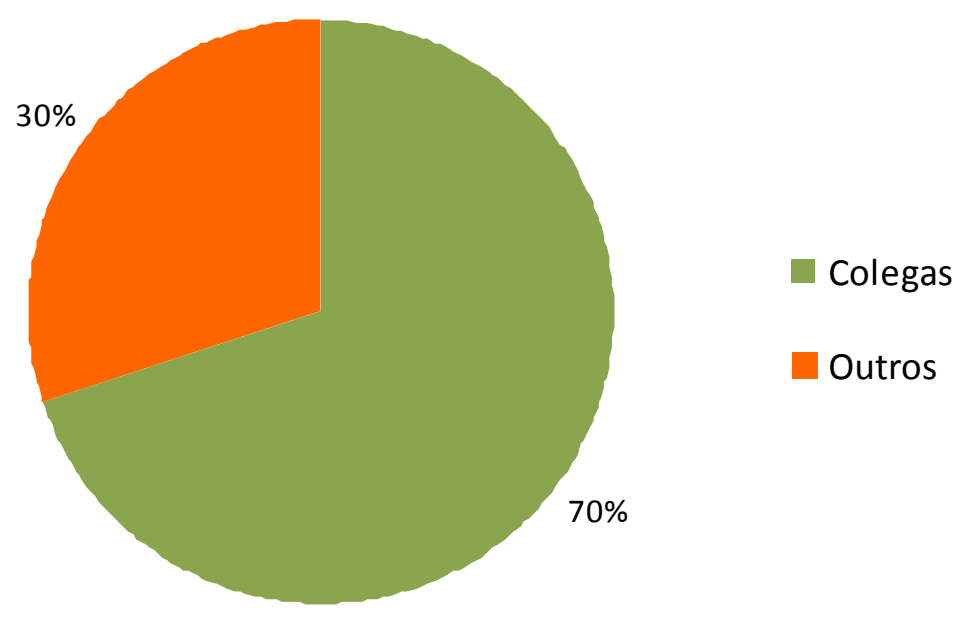

Pela figura 7 ficou evidenciado que a maioria dos professores trabalharam o tema racismo em sala.

Figura 7 - Os professores já trabalharam o tema em sala?

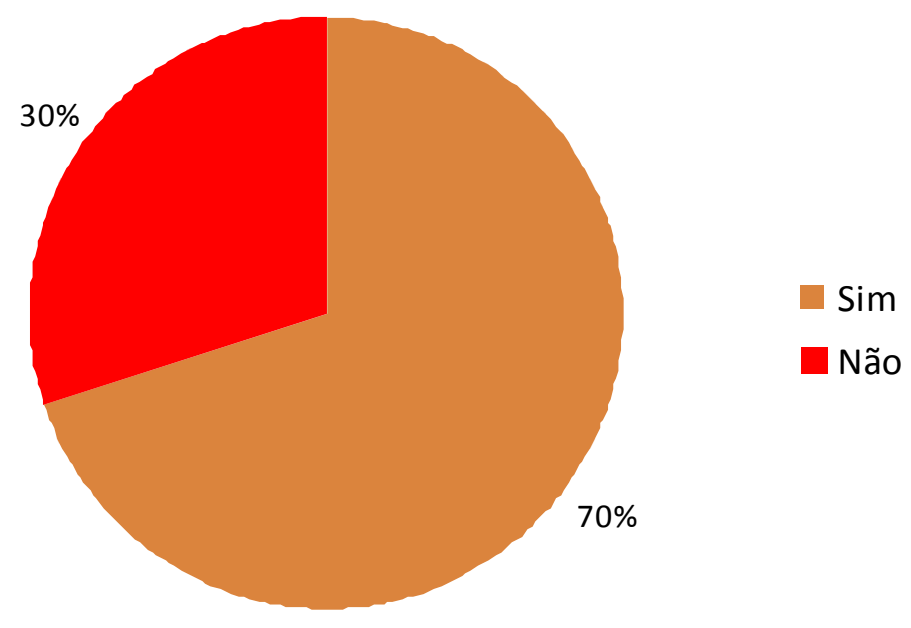


Através da figura 8, ficou evidenciado que o tema foi trabalhado em $43 \% \mathrm{com}$ palestras, $33 \%$ com filmes e $24 \%$ responderam outros.

Figura 8 - Como foi trabalhado o tema?

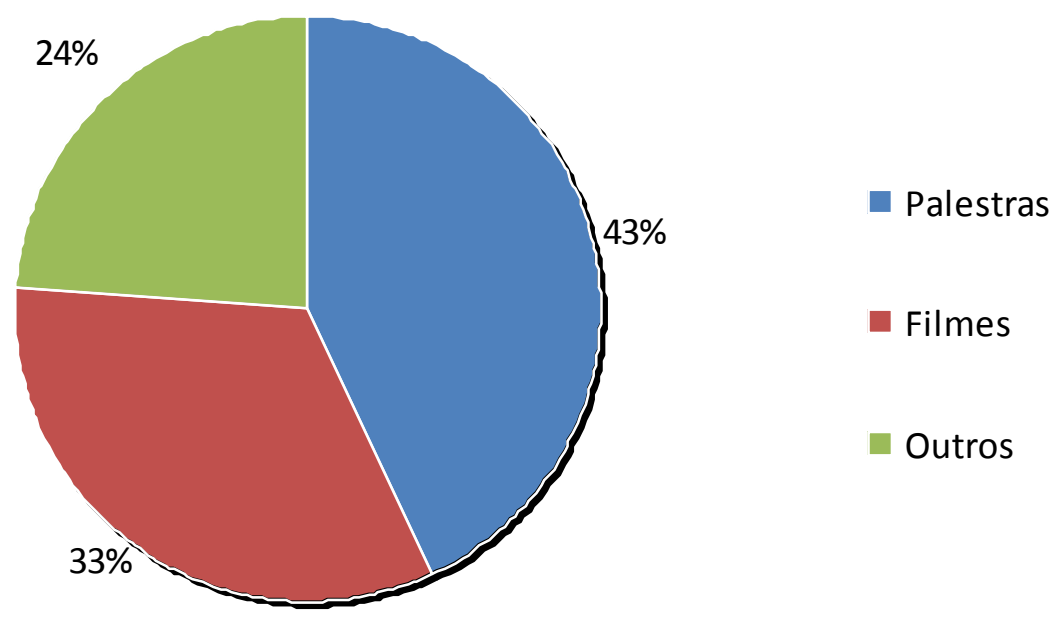

\section{Considerações finais}

Pode-se perceber que a maioria dos entrevistados sabe o que é discriminação e bullying e já os perceberam na escola, assim como a maioria dos professores já trabalharam o tema em sala, seja por meio de filmes, palestras e apresentações.

Assim, verificando as atas de reuniões do conselho escolar, percebe-se que é importante que os gestores da Escola Estadual Irmã Lucinda Facchini dialoguem e busquem saídas para a desconstrução da discriminação racial no espaço escolar e no seio da sociedade brasileira.

O currículo deve ser revisto, repensado e rediscutido, já que nele percebe a falta de visibilidade e reconhecimento de conteúdos que envolvem a questão negra.

Finalizando, a educação deve ajudar os alunos a se habituarem à diversidade humana e a valorizarem as diferenças. Os professores devem estar preparados e capacitados para trabalharem no cotidiano escolar o contato com alunos negros, brancos e indígenas.

Compartilhar é discutir experiências, sucessos e fracassos é fundamental para se trabalhar questões relacionadas à discriminação no ambiente escolar.

Assim, há a possibilidade de sugestão aos gestores de programar projetos pedagógicos e atividades que abordem o tema da discriminação racial, que não fiquem tão somente nos temas transversais. O processo educativo deve ser uma via de acesso ao resgate da autoestima e das imagens distorcidas, porque a escola é o ponto de encontro e de embate das diferenças étnicas, é um meio para minimizar e prevenir a exclusão da comunidade negra. 


\section{Referências}

CAVALLEIRO. Eliane. Valores civilizatórios dimensões históricas para uma educação anti-racista. In: MEC. Secretaria da Educação Continuada, Alfabetização e Diversidade. Orientações e ações para a educação das relações étnico-raciais. Brasília: Secad, 2006.

COSTA. Cândida Soares. O negro no livro didático de língua portuguesa: imagens e percepções de alunos e professores. Cuiabá: UFMT/IE, 2007.

LOPES, Ana Lúcia. Currículo, escola e relações étnicorraciais. In: Educação africanidades. Brasília: MEC/Secad/UNB/Cead, 2006.

MENEZES. Waléria. $O$ papel do gestor escolar. Disponível em: <http://webatrigos.com.br>. Acesso em 25 maio 2009.

SILVA. Hédio Jr. Discriminação racial nas escolas: entre a lei e as práticas sociais. Brasilia: Unesco, 2002.

Jacilda de Siqueira Pinho é graduada em Pedagogia pela Universidade Federal de Mato Grosso e em Letras pela Universidade do Estado de Mato Grosso. Professora efetiva da rede pública estadual de Diamantino-MT, atua na área de Língua Portuguesa e Literatura. Atualmente, é coordenadora pedagógica na Escola Estadual Plácido de Castro.

Endereço: Rua do Aparício, 266 - 78400-000 - Diamantino - MT.

e-mail: jacildapinho@yahoo.com.br.

Recebido em 22 de fevereiro de 2013.

Aceito em 19 de dezembro de 2014. 